The International Journal of
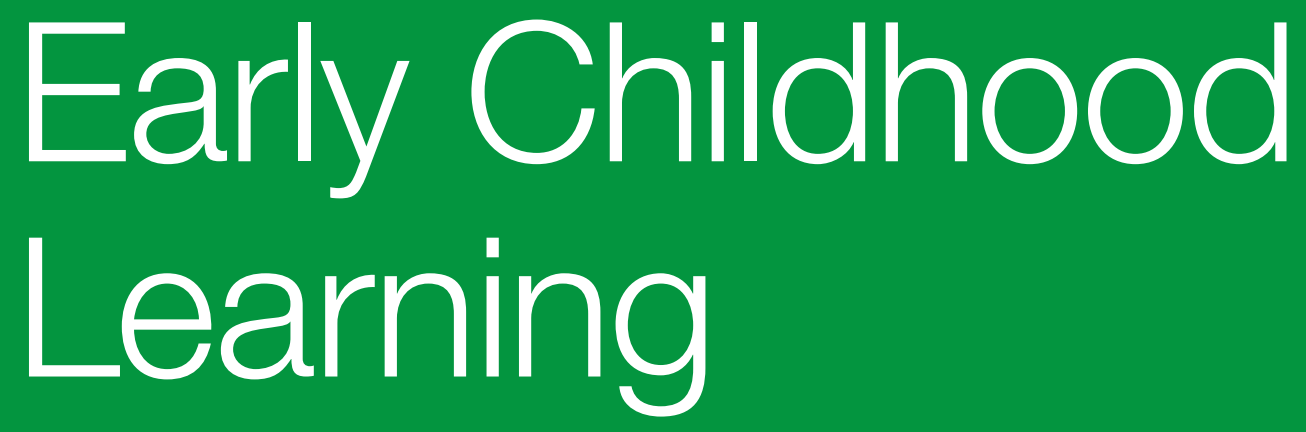

Arts Learning in Australian Kindergartens One Case Study Exploring the Scaffoding of Domain Specific Knowledge

SUSANNE GARVIS 
THE INTERNATIONAL JOURNAL OF EARLY CHILDHOOD LEARNING

http://thelearner.com/

First published in 2013 in Champaign, Illinois, USA

by Common Ground Publishing

University of Illinois Research Park

2001 South First St, Suite 202

Champaign, IL 61820 USA

www.CommonGroundPublishing.com

ISSN: $2327-7939$

(C) 2013 (individual papers), the author(s)

(C) 2013 (selection and editorial matter) Common Ground

All rights reserved. Apart from fair dealing for the purposes of study, research, criticism or review as permitted under the applicable copyright legislation, no part of this work may be reproduced by any process without written permission from the publisher. For permissions and other inquiries, please contact <cg-support@commongroundpublishing.com>.

The International Journal of Early Childhood Learning is a peer-reviewed scholarly journal.

Typeset in CGScholar.

http://www.commongroundpublishing.com/software/ 


\title{
Arts Learning in Australian Kindergartens: One Case Study Exploring the Scaffolding of Domain Specific Knowledge
}

\begin{abstract}
Susanne Garvis, Griffith University, Australia
Abstract: Arts education is an important area of learning for young children. The arts allow children to explore and make meaning of the world around them. It is also a time when children start to develop domain-specific knowledge about the arts. This paper explores the development of domain-specific knowledge about the arts in kindergarten classrooms in Queensland, Australia. It explore the way the teacher embeds domain-specific knowledge about the arts in her kindergarten classroom. Findings suggest the teacher is an important part of learning about domain-specific knowledge. Young children are challenged by the teacher to develop greater clarity and thought about the arts. If the teacher is not there to support and challenge ideas, while children are creative and masters of their own play, their development in the arts is limited.
\end{abstract}

Keywords: Arts, Early Childhood, Domain Knowledge

\section{Introduction}

$\mathrm{T}$ The role of the early years teacher is to enhance the development of domain-intrinsic knowledge in young children (Pramling Samuelsson et al. 2009). Domain-intrinsic knowledge is the specific knowledge related to a key area of learning. Teachers often introduce such tools through the terminology in which they phrase their questions to children to enhance domain-instrinsic knowledge, especially in the arts (see Pramling and Wallerstedt 2009). According to Pramling Samuelsson et al. $(2009,133)$ "these distinctions and concepts become the tools through which children develop their aesthetic perception".

The role of the early childhood teacher also extends to advising parents about suitable curricula activities for the arts. The arts are defined as dance, drama, media, music and visual arts. Olson and Hyson $(2005,67)$ stated "we should do a better job communicating our role as reliable credible sources of information and support". Early years teachers have the capacity to build strong links between school and home for the child's arts environment. If children are actively engaged with the arts in both environments, a continuum of learning develops.

It is important for early childhood teachers to know how to develop domain-specific knowledge in young children. Teachers need to have an understanding of how they can scaffold young children's learning in the arts to extend their understanding. The arts are an important area of the curriculum in Australian early childhood education. Limited time however is devoted to the arts in early childhood teacher education. This means early childhood teachers may not have adequate skills to support young children with arts experiences. It is for this reason that research within Australia needs to know how experienced teachers support arts experiences in their early childhood classrooms. By understanding exact skills used, these can be recognized and provided to less experienced teachers to encourage arts engagement in the classroom.

Using a case study approach, this paper explores the development of domain-specific knowledge about the arts in kindergarten classrooms (children aged 3.5 years) in Queensland, Australia. The study was interested in answering the question: How does an early childhood teacher scaffold the development of arts domain-intrinsic knowledge in her classroom? It explores the way one teacher embeds domain-specific knowledge about the arts in her kindergarten classroom on a daily level. Data was analysed using a themed approach.

Findings suggest the teacher is an important part of learning about domain-specific knowledge in the arts. In this case study, young children are challenged by the teacher to develop

The International Journal of Early Childhood Learning Volume 19, 2013, thelearner.com, ISSN 2327-7939 
greater clarity and thought about the arts. If the teacher is not there to support and challenge ideas, while children are creative and masters of their own play, their development in the arts may be limited.

\section{Literature Review}

\section{Early Years Reform in Australia}

In recent years Australia has seen a trend towards an increased use of formal early childhood education and care settings. With so many children attending early childhood services, it is important that there are consistent standards of quality. Federal and state/territory governments have responded with reform agendas designed to improve the quality of early childhood education and care. The agreed reform covers children from birth to eight years and aims to improve the health, safety, early learning and wellbeing of all children and better support disadvantaged children to reduce inequalities (Department of Education, Employment and Workplace Relations 2011).

Early childhood education and care has been a concern of many countries in recent times (OECD 2006). Over the past decade and a half, a rapid growth in early childhood education and care provisions has a occurred in Australia, with a higher level of Commonwealth Government commitment given after 2007 (Department of Education, Employment and Workplace Relations 2009). A key initiative was the endorsement of the National Early Childhood Investment Strategy- Investing in the Early Years in 2009 by the Council of Australian Governments (COAG). The strategy is "a collaborative effort between the Commonwealth and the state and territory governments to ensure that by 2020 all children have the best start in life to create a better future for themselves and for the nation" (COAG 2009).

The Early Years Learning Framework (Department of Education, Employment and Workplace Relations 2009) is part of the Council of Australian Government's (COAG) reform agenda for early childhood education and care and is a key component of the Australian Government's National Quality Framework for early childhood education and care. It underpins universal access to early childhood education and will be incorporated in the National Quality Standard. Universal access means all children.

The Early Years Learning Framework describes the principles, practice and outcomes essential to support and enhance young children's learning from birth to five years of age. The Framework has a strong emphasis on play-based learning as the best vehicle for children's learning and development. The Framework also recognizes the importance of communication and language and social and emotional development.

In October, 2008, the Queensland Government announced the plan Toward Q2 Tomorrow's Queensland: Delivering World Class Education- Starting Early to ensure all Queensland children have access to a kindergarten program by 2014. This is part of the Council of Australian Governments agreement for universal access for all children to quality early childhood education and care prior to formal schooling. In Queensland this initiative includes the creation of an extra 240 kindergarten services, with 108 new services expected to open in 2012. The kindergarten services are scheduled to open in areas of need to cater for kindy-age children not currently accessing centre-based early childhood education and care services (around 12,000 children)(Queensland Government 2008). This means that since all children have access to kindergarten, they are also required to have access to quality arts experiences supplied by the teacher. It is expected that children actively engage in arts experiences in the early years as part of the Early Years Learning Framework (COAG 2009). Little is currently known is Australia however of the types of arts experiences that take place, given the recent changes is government policy of allowing universal access to all children in the year before formal schooling. 


\section{Arts with Young Children}

Arts engagement is an important area of learning for young children. Eisner (2002) argues that through active engagement with arts experiences children can develop their senses and their imagination:

The senses provide the material for the creation of consciousness, and we, in turn, use the content of consciousness and the sensory potential of various materials to mediate, transform, and transport our consciousness into worlds beyond ourselves (17-18).

Many Australian documents in early childhood currently acknowledge the importance of arts in education (Garvis \& Pendergast 2011). The expectation of arts education was made public by the Australian Ministerial Council on Education Employment, Training and Youth Affair (MCEETYA) releasing a statement entitled the National Education and the Arts Statement (2005) for early childhood, primary years, middle years and senior years of schooling. Building on from the Adelaide Declaration on National Goals for Schooling in the Twenty-First Century (1999), this statement was designed to foster a culture of creativity and innovation in Australian schools. It acknowledged that an education rich in the creative arts maximises opportunities for learners to engage with innovative thinkers and learners, emphasizing not only creativity and innovation, but also the values of broad cultural understandings and social harmony that the arts can engender. This is similar to UNESCO's Road Map for Arts Education (2006), with arts considered a necessity for skill development in the $21^{\text {st }}$ century, allowing nations to develop the human resources necessary to tap their cultural capital.

In the Australian National Education and Arts Statement (2005) it acknowledged that arts experiences enhanced all phases of schooling from early childhood to senior school. All students, irrespective of their location, socio-economic status or ability should have equal opportunities to participate in arts-rich schooling systems (MCEETYA 2005). School-based arts experiences should be diverse, based on models of effective practice, and embedded from the early years through to graduation in order to unlock the creative potential of young people (MCEETYA 2005). In order to foster this crucial change in arts education, the statement acknowledges the necessity to foster the skills and knowledge of teachers of children, especially in the early years.

There is a common belief that teachers should not interfere with the arts making of young children. The belief suggests children are best left unhindered in their arts development. Richards (2007) challenges this view, arguing that learning in the arts is a social, cultural and historical act. In this view, early childhood professionals recognize the social and interactive nature of children's arts experiences. Pramling Samuelsson et al. $(2009,133)$ suggest children are creative and masters of play, but in order to become aware of distinctions, variation and invariance of the phenomena of the arts, children must be challenged by the teacher in order to clarify and develop their thought”. Accordingly, the goal is to help children develop domainintrinsic knowledge about the arts, rather than merely using the arts as a means for developing art-extrinsic knowing (Pramling Samuelsson et al. 2009). Early childhood professionals play an important role for young children in helping provide quality arts learning experiences.

The theoretical framework for this study is developmental pedagogy (Pramling Samuelsson and Asplund Carlsson 2007; 2008) with the following specific features: meta-cognitive dialogues, learning act vs. learning object, discernment and variation. The act of learning (i.e., how children learn) does not stand in a simple relation to how children experience or perceive an object (ie. what children learn). According to Pramling Samuelsson et al. $(2009,124)$ "to learn means to change from one way of experiencing something to another way of experiencing the same thing". Meta-cognitive dialogue is a tool that the teacher can use to make children aware of something particular. In order to be able to focus on an object of learning, something specific needs to be discerned (Gibson and Gibson 1955) from something else. A necessary condition for discernment is variation (Marton, Runesson, and Tsui 2004). If children are supposed to learn to 
move in relation to music, or follow the pulse of the music, pulse must be experienced as pulse by the children (Pramling Samuelsson et al. (2009).

The developmental pedagogical approach has proven to be powerful in contributing to developing children's understanding of different aspects of their surrounding world. It has been applied to children's learning in different domains such as literacy, numeracy, nature and culture. In 2009, Pramling Samuelsson et al. (2009) applied the approach to the arts. Sine then, few studies have used this approach. At a general level, the role of the teacher is to create opportunities, situations, tasks, etc. that challenge children's ways of experiencing or making sense of something (Pramling 1994; Pramling Samuelsson and Asplund Carlsson 2007). In this study developmental pedagogy will be used a as a tool to analyse teacher practice.

\section{Focus of Study}

This study focuses on the arts practice that occurred in one kindergarten over a period of a day. It is designed to document and analyse current arts activities (if any) that occur following the reforms in early years education. The findings are focused on identifying examples of developing domain-intrinsic knowledge for the arts with young children in kindergartens. The research question is:

How does an early childhood teacher scaffold the development of arts domain-intrinsic knowledge in her classroom?

\section{Context of Study}

This study was conducted in two kindergartens in South East Queensland, Australia. Some of the children who attend the kindergartens enter the preparatory classrooms explored.

In Queensland (state within Australia), kindergarten is for children aged 3.5 years. While it is not compulsory, kindergarten is part of the universal access for early childhood education agreement. This means all children across the state have access to a place in an early childhood service. The universal access agreement acknowledges that by 2014, all children (kindergarten age) across Australia in all states and territories will have access to 15 hours of a quality early childhood education program with a qualified teacher. This means that the child is supposed to be engaged in a quality early childhood program of learning that includes arts as an important area of learning.

\section{Methods}

This study used a case study method to college data. Case study methodology is ideal when a holistic, in-depth investigation is needed (Feagin, Orum \& Sjoberg, 1991). Extensive data was collected in the form of observations, interviews and field notes over the period of a week in each kindergarten. Observations were made of the teacher's arts practice throughout the day and collected as running records. A 20 minute interview was conducted with the teacher at the end of the week. Field notes were also collected throughout the week. The three points of data could then be triangulated together.Data was analysed trying to find the three specific features of developmental pedagogy; (1) meta-cognitive dialogues, (2) learning act vs. learning object, and (3) discernment and variation. It was analysed using a themed analysis approach, looking for chunks of meaning. The initial search was for "chunks of text about particular themes" that were meaningful and relevant to the student and "importantly and repeated” (Riessman, 1993). 


\section{Findings}

\section{Meta-cognitive Dialogues}

From the field notes and observations, it become evidence that the teacher's questions and conversations became important in scaffolding arts experiences in the classroom. The teacher used a technique of meta-cognitive dialogues. Meta-cognitive dialogues are all about the communication and interaction the teacher and the children get involved in. In the observed kindergarten, it was assessing the meta-talk that took place between the children and teacher. The meta-talk was an organic process and grew out of the children's interests in an arts activity. Every day the kindergarten teacher would provide examples of her meta-cognitive dialogues linked to the teaching of domain-intrinsic knowledge. This talk was either with individual children or in-group situations, such as mat time when all children were seated on the floor.

An example is given below, highlighting the way the teacher uses questioning to develop domain-intrinsic knowledge about music with the children. The children were seated around the circle in group time.

Sam (aged 3) raises his hand.

Sam: Miss K, I could feel my heart beat when singing.

Miss K: Sam what did it feel like?

Sam: It came from here (points to chest with thumb) and it went boom, boom boom.

Miss K: So it went boom, boom boom and kept going?

Sam: Yep it went boom!

Other children touch their chests and raise their hands.

Miss K: What did you feel?

Kelly: I felt the song.

Bill: Me too.

Tom: Me three. I felt the heart beat of the song.

Miss K: So why did this song have a heart beat?

Max: To keep it living so it didn’t die.

Sam: All songs live so they must have a beat.

In this example we can see the way the teacher asks questions to increase the young children's knowledge about the beat of the music. Building on from Sam's inquiry, the teacher was able to use the moment to teach all the children about their own heart beat and link that understanding to the beat of the music.

We can start to see the importance of the teacher in helping children develop their domainintrinsic knowledge about music. This teacher's skill, in part, consists of being able to get children to express themselves and then to take the child's perspective, that is, to understand the child's sense-making (Doverborg and Pramling Samuelsson 2000). In this example we can see the teacher working beside the children and interpreting what they are saying. 
The teacher used different techniques of variation with art to help the children by developing an awareness of various contrasting visual art features. The teacher would use meta-dialogue to extend the child's understanding.

One example shows the kindergarten teacher using different width brushes in painting to explore brush sizes and the resultant lines in painting. The children explored different brush sizes when trying to paint the same picture of their house to see the differences in stroke size.

Miss P: What are you going to use to paint your house?

Thomas: A brush.

Miss P: Which brush?

Caitlin: This brush. The usual brush.

Miss P: Is it big or small?

Caitlin: Small.

Miss P: I wonder what would happen if you use a different sized brush?

Caitlin chooses a different size brush and begins paining.

\section{The Act and Object of Learning in the Arts}

In developmental pedagogical theory, "to learn means to change from one way of experiencing something to another way of experiencing the same thing" (Pramling-Samuelsson et al. 2009). The object of learning is the understanding that teachers want to develop in children. In the case study, the kindergarten teacher would often make it known to the parents and myself what the objects of learning were for the day (the kindergarten teacher called these knew knowledges and skills). In regard to the arts, the objects of learning moved beyond simple understanding of 'this is arts' to understanding basic features about each of the arts domains. The kindergarten teacher was very clear about their intentions for music in the classroom. As one kindergarten teacher commented:

For music, I want children to identify, analyse and respond to musical patterns, tones, colours, structures and expressive elements over the semester.

The kindergarten teacher used a variety of arts activities throughout the week to achieve these outcomes. This included focused teaching segments, free arts play for the children (inventing songs and playing with musical instruments, creating art in a variety of mediums), routines, transitions, and also listening to parents and community members who volunteered to play musical instruments, share dances, monologues and art works in the classroom. The act and object of learning the arts featured throughout the daily planning with the children. The role of the teacher was to develop the object of learning.

\section{Discussion and Conclusion}

This study has shown the kindergarten teacher in the case study scaffolded the children's domain-intrinsic knowledge in the arts through the use of two technique. She enacted specific talk that was directed towards the children extending their thinking. The skilled teachers did this through their use of meta-talk with the children, providing variation for learning and also acknowledging differences between the act and object of learning the arts. She knew how to ask 
questions and prompt the children in their thinking. The questions encouraged the children to develop and clarify their thinking about the arts.

Without the teachers' involvement in children's arts learning, young children cannot be challenged in their understanding about the arts. The role of the kindergarten teacher in this case study was to challenge the young child in order to clarify and develop thought further.

It is important for kindergarten teachers to have a working awareness of powerful tools to help support the learning of young children in each of the subject areas. This study identified elements from developmental pedagogy that enabled the kindergarten teacher to extend the children's understanding in their every day teaching. All early years teachers need an in-depth knowledge of suitable pedagogy for children. It is important that these skills are taught during teacher education.

More research is needed into ways to support early years teachers to develop the skills necessary to support and develop children's understanding about the arts. Greater understanding is also needed as to why the arts is given equal footing in a kindergarten classroom but not in primary school classrooms across Australia. Why it is that the kindergarten teacher has the developed knowledge about how to teach the arts while many primary teachers do not? What happens to children's learning if there domain-intrinsic knowledge for the arts is not extended in the primary school classroom? What happens to the way children learn as the move from a metatalk approach with the teacher to a formalized teaching style in the arts? While there is a strong awareness that the arts is important for young children and an integral part of life in a culture, more research is necessary into exploring the ways that teachers can develop arts knowledge and ideas for young children. 


\section{REFERENCES}

Department of Education, Employment and Workplace Relations (DEEWR). 2009. Belonging, Being \& Becoming: The Early Years Learning Framework for Australia. Canberra: DEEWR.

Department of Education, Employment and Workplace Relations, 2011. National Quality Framework Policy Agenda. Accessed September, 62011. http://www.deewr.gov.au/Earlychildhood/Policy_Agenda/Pages/home.aspx

Eisner, E. 2002. The Arts and the Creation of Mind. New Haven, CT: Yale University Press.

Garvis, S., \& Pendergast, D. (2011). An Investigation of Early Childhood Teacher Self-Efficacy Beliefs in the Teaching of Arts Education. International Journal of Education and the Arts, 12, no 6.

Gibson, J.J., and E.J. Gibson. 1955. "Perceptual Learning: Differentiation or Enrichment?" Psychological Review 62, no. 1, 32-41.

Marton, F., U. Runesson. and A.B.M. Tsui. A.B.M. 2004. "The Space of Learning." In Classroom Discourse and the Space of Learning, edited by F. Marton and A.B.M. Tsui, 3-40. Mahwah, NJ: Lawrence Erlbaum.

Ministerial Council on Education, Employment, Training and Youth Affairs. 2005. National Education and the Arts Statement. Accessed January 27, 2007. http://www.curriculum.edu.au/mceetya/national_education_and_the_arts_statement,29 81.html.

OECD. 2006. Starting Strong II: Early Childhood Education and Care. Paris, France: Organisation for Economic Development.

Olson, M., and M. Hyson. 2005. NAEYC Explores Parental Perspectives on Early Childhood Education. Young Children, 66-68.

Pramling, N., and C. Wallerstedt. 2009. Making Musical Sense: The Multimodal Nature of Clarifying Musical Listening. Music Education Research 11, no. 2, 135-51.

Pramling Samuelsson, I., and M. Asplund Carlsson. 2007. Spielend lernen: Stärkung lernmetodischer kompetenzen. Trans. S. Werner. Troisdorf, Germany: Bildungsverlag Eins.

Pramling Samuelsson, I., and M. Asplund Carlsson. 2008. "The Playing Learning Child: Towards a Pedagogy of Early Childhood.” Scandinavian Journal of Educational Research 52, no. 6, 623-41.

Pramling Samuelsson, I., M. Aspland Carlsson, B. Olsson, N. Pramling, and C. Wallerstedt. 2009. "The Art of Teaching Children the Arts: Music, Dance and Poetry with Children Aged 2-8 Years Old.” International Journal of Early Years Education 17, no. 2, 119135.

Queensland Government. 2008. Toward Q2 Tomorrow’s Queensland: Delivering World Class Education- Starting Early. Accessed 2 June, 22011. http://www.towardq2.qld.gov.au/library/pdf/tomorrow/Education_Starting_early.pdf

Queensland Government. 2010. Queensland Kindergarten Learning Guideline. Accessed 3 June, 3 2011. http://www.qsa.qld.edu.au/downloads/early_middle/qklg.pdf

Richards, R. D. 2007. "Outdated Relics on Hallowed Ground: Unearthing Attitudes and Beliefs about Young Children’s Art.” Australian Journal of Early Childhood, 32, no. 4, 22-30.

\section{ABOUT THE AUTHOR}

Dr. Susanne Garvis: Susanne Garvis is an early childhood lecturer at Griffith University, Gold Coast. Her current research focus explores arts making in early years contexts for children aged birth to five years. 
The International Journal of Early Childhood

Learning is one of ten thematically focused journals

in the family of journals that support The Learner

knowledge community-its journals, book series,

conference and online community. It is a section of The

International Journal of Learning.

The journal investigates the dynamics of learning in the first seven years of life.

As well as papers of a traditional scholarly type, this journal invites presentations of practice-including documentation of early childhood learning practices and exegeses of the effects of those practices.

The International Journal of Early Childhood Learning is a peer-reviewed scholarly journal.

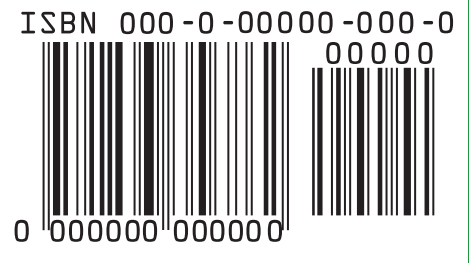

